\title{
Küçük Ölçekli Francis Türbini Tasarımı Ve Hesaplamalı Akışkanlar Dinamiği Analizi
}

\section{Small Scale Francis Turbine Design And Computational Fluid Dynamics Analyses}

\author{
${\text { Hakan } \text { Yontar }^{1} \text { iD }, \text { Salih Karaaslan' }}^{1}$ iD , Nuri Yücel ${ }^{1}$ \\ ${ }^{l}$ Gazi Üniversitesi, Mühendislik Fakültesi, Makine Mühendisliği Bölümü, 06570, Ankara, TÜRKIYE
}

$\ddot{O} z$

$\mathrm{Bu}$ çalışmada, küçük ölçekli Francis türbini bileşenlerinin tasarımı ve hesaplamalı akışkanlar dinamiği analizleri gerçekleştirilmiştir. Bovet yöntemi kullanılarak çark kanadı analitik ve ampirik bağıntılar ile tasarlanmıştır. Çark ve ayar kanadı merdiyenel profilleri ANSYS Bladegen V17.0'da oluşturulmuştur. Ağ yapısı ANSYS Turbogrid ile oluşturulmuştur. Salyangoz ve emme borusu tasarımlarının geometrileri Solidworks 2013'de oluşturulmuştur. Türbin bileşenleri ve tüm türbin için hesaplamalı akışkanlar dinamiği (HAD) analizleri k- $\varepsilon$ türbülans modeli kullanılarak yapılmıştır. HAD analizleri kararlı çalışma şartları için gerçekleştirilmiştir. Analizlerin sonucunda basınç dağılımları ve akış hız çizgileri elde edilmiştir. Türbine ait elde edilen verim değeri incelenmiştir. Analitik yöntemler kullanılarak elde edilen verim ile HAD analiz sonuçlarındaki verim karşılaştırıldığında, \%2 fark olduğu görülmüştür.

\section{Anahtar Kelimeler}

"Francis Türbini, HAD, Turbomakina, Türbin Tasarımı"

\begin{abstract}
In this study, the design and numerical analysis of small scale Francis turbine components were performed. According to the Bovet method, analytical calculations of single blade were performed. Runner and wicket gate meridional profiles were created in ANSYS Bladegen V17.0. Grid models were created in ANSYS Turbogrid V17.0. The geometries of the spiral case and draft tube designs were created in Solidworks 2013. Computational fluid dynamics (CFD) analyzes for turbine components and turbine were performed in steady state with $\mathrm{k}-\varepsilon$ turbulence model. As a result of the CFD analyses, pressure distributions and flow lines were obtained. The efficiency of the turbine was examined. When the efficiency in design and CFD analysis results were compared, it was seen that there was a difference of $\% 2$.
\end{abstract}

\section{Key Words}

"Francis Turbine, CFD, Turbomachinery, Turbine Design" 


\section{Giriş}

Dünya'da enerjiye olan talep sanayileşme, kentleşme ve nüfus artışının sonucu olarak her geçen gün artmaktadır. Enerji kaynakları arasında hidroelektrik santralleri; çevreye uyumlu, temiz, yenilenebilir, yüksek verimli ve işletme giderleri düşük olan bir kaynaktır. Dünya'daki elektrik üretiminin \%17'si hidroelektrik ile gerçekleşmektedir(The USGS Water Science School). Hidroelektrik en önemli ve en çok kullanılan yenilenebilir enerji kaynağıdır. Hidroelektrik santrallerde kullanılan türbinler çarpma etkili ve reaksiyon türbinleri olarak 2 ana tipte sınıflandırılır. Debi ve düşü değerleri kullanılarak bu sınıflandırma şekil 1'deki gibi yapılmaktadır. Francis türbinleri türbin seçim tablosunda da görüldüğ̈̈ gibi geniş çerçevedeki debi ve düşü kullanımı ile en çok kullanılan hidrolik türbin tipidir. Bu türbinin en önemli parçası potansiyel enerjiyi mekanik enerjiye çeviren çark kısmıdır. Genel olarak türbin çarkları karışık geometrilere sahiptir. Bu nedenle, çark tasarımları ve üretimleri yüksek verim elde etmek için önemlidir.

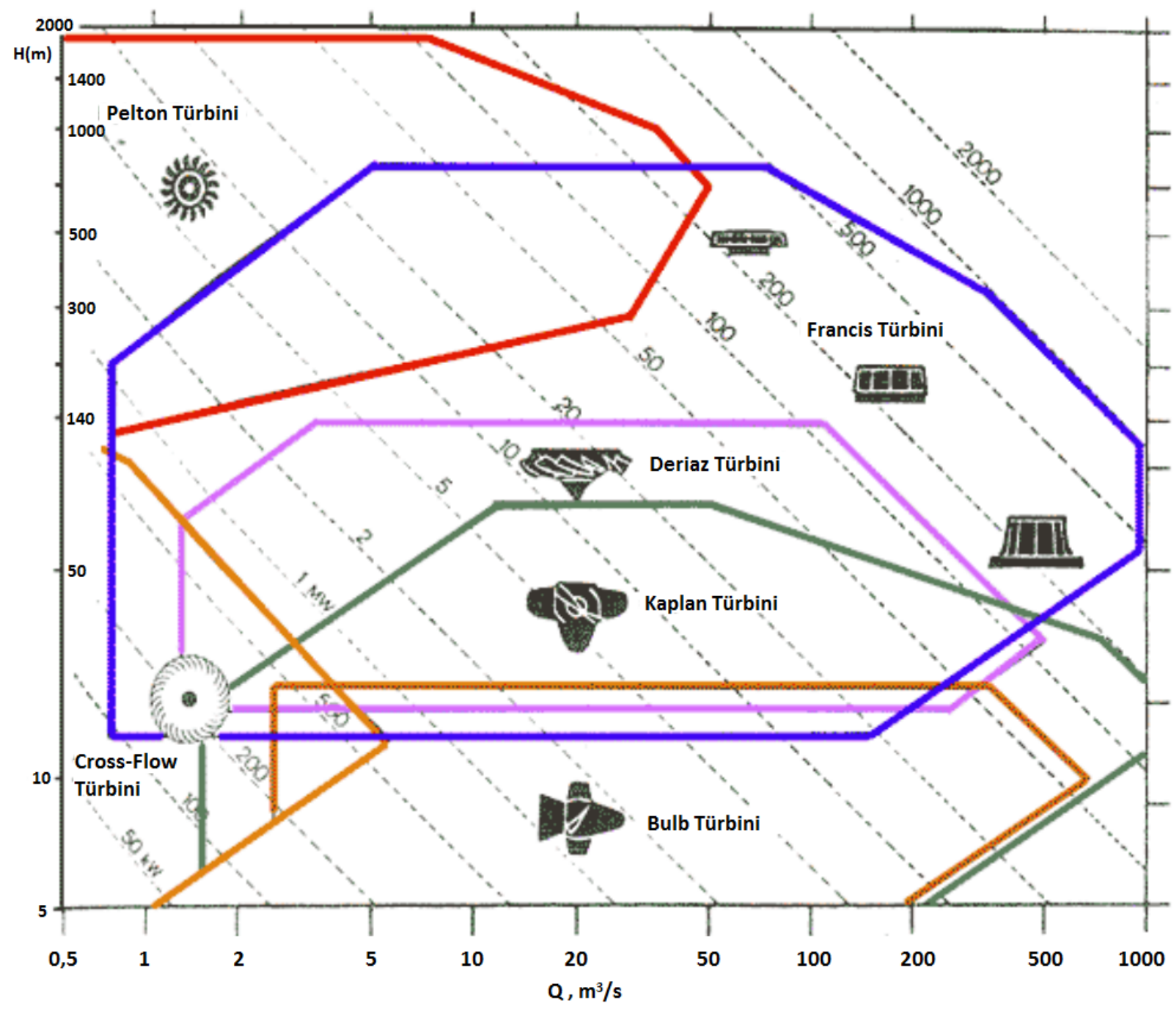

Şekil 1. Debi Ve Düşü Değerlerine Göre Türbin Seçim Tablosu(Haas\&Hiebert\&Hoatson, 2014)

Çark tasarımı ile ilgili literatürde çok fazla araştırma mevcuttur. Bovet yöntemi de bunlardan biridir. Bu yöntemde, ampirik denklemler kullanılarak Francis türbin çarkı parametreleri elde edilmiştir. Türbinin tüm ölçülerini tanımlamak için boyutsuz özgül hız değeri ana parametre olarak kullanılmıştır(Bovet, 1963).

Türbin tasarımı ile ilgili literatürdeki araştırmalar incelendiğinde; Ruprecht, Heitele ve Helmrich (2014) tarafından Francis tipi bir türbinin modellemesini zamana bağlı olarak çözümlenmiştir. Hesaplamalar Reynolds ortalama Navier-Stokes (RANS) denklemleri kullanılarak gerçekleştirilmiştir. Her komponent bağımsız olarak hesaplanmıştır. Daha sonra tüm türbine ait hesaplamalar yapılmıştır. Hesaplama alanı dört bileşene(salyangoz, çark, emme borusu ve ayar kanatları) ayrılmıştır. Her bileşen için bağımsız ă̆ yapıları oluşturulmuştur ve farklı bileşenlere ait ă̆ yapıları üst üste bindirilmiştir. Oluştulan bu ağ yapısı 2 milyondan fazla eleman içermektedir. Hesaplamalar kısmi yük ve optimum olmak üzere iki farklı işlem noktası için gerçekleştirilmiştir. Bütün hesaplamalar 24 sabit ve ayar kanatlı ve 13 çark kanatlı bir türbin için gerçekleştirilmiştir. Bütün bu hesaplamalarda amaç önemli nicel sonuçlar elde etmek değil bir uygulanabilirlik çalışması gerçekleştirmektir. Türbinler için bu ve benzeri hesaplamalar, simülasyonların uygulanabilir olduğunu, beklenen yük ve dinamik kuvvetler düşünüldüğünde nicel olarak doğru sonuçların elde edildiğini göstermektedir. Daha doğru çözümler için daha iyi ağ yapısı oluşturulması gerekmektedir. Hesaplamalardaki en büyük zorluklardan biri, başlangıç periyodunda ve frekanslarda çok farklı olan akış fenomenlerinin varlığıdır (Ruprecht\&Heitele\&Helmrich). Liv vd. (2010) yapılan çalışmada Francis türbini tasarımını zamana bağlı olarak HAD yardımı ile çözümlenmiştir. Reynolds ortalama süreklilik ve Navier Stokes denklemlerini ve dönme sistemi momentum denklemlerini kullanarak çark bölgesinin korunum denklemlerini elde etmişlerdir. Çalışmada RNG k-E türbülans modeli kullanılmıştır. Simulasyon 
sonuçları ve deney sonuçları karşılaştırıldığında her iki verinin de birbiriyle uyumlu olduğunu ve hidrolik türbine ait tüm parametrelerin değişiminin geçici süreç boyunca tahmin edilebileceğini göstermektedir. Neopane, vd. (2007) tarafından yapılan çalışmada, kum erozyonu etkisini en aza indirmek için Francis türbinine alternatif bir tasarım önerilmiştir. Türbinin tasarımını iki ana aşamada gerçekleştirilmiştir. İlk adım, deneysel verilere ve Euler'in türbin denklemine dayanan ilk tasarımdır. İkinci adım, ayar kanatlarından çark kanat girişine doğru tek düze bir akış alanının varsayımına dayanan tasarımın ince ayarlanması için üç boyutlu HAD analizidir. Francis çarkı prototipinin son ayarlamaları için sayısal yöntemler kullanılmıştır. HAD ile birlikte yinelemeli bir tasarım yöntemi kullanılmıştır. Huang vd. (2006) Swiderski, Ji, Tung ve Riley; bir hidroelektrik santralindeki kavitasyon sorunlarını çözmek için bir durum çalışması gerçekleştirmiştir. Francis türbini ünitesi 10 sabit kanat, 16 adet ayar kanadı ve 14 kanatlı bir çarktan oluşmaktadır. Tüm ağ yapısı TASCgrid (CFX-TASCflow) yazılımı ile oluşturulmuştur. Proje kapsamında yapılan çalışmalar sonucunda sadece çark değiştirilmiştir. CFX kullanılarak optimize edilen yeni çarkın aşırı yükler altında kavitasyonu ortadan kaldırdığı görülmüştür. Odesola ve Oririabre (2013); 5 kW gücünde bir Francis türbin çarkını hesaplamalı akışkanlar dinamiği yaklaşımı ile geliştirmişlerdir. Bu çalışmada $6 \mathrm{~m}$ net düşü ve $0.244 \mathrm{~m}^{3} / \mathrm{s}$ hacimsel debi şartları altında tüm türbin bileşenleri (salyangoz, sabit/ayar kanatları, emme borusu) iki farklı ticari yazılımın karşılaştırmalı olarak kullanılmasıyla sayısal olarak irdelenmiştir. Teran vd (2016); 500 kW'lık bir Francis türbininin yapay ağ yöntemi ile geliştirilmiş bir kod vasıtası ile daha verimli hale getirmeye çalışmıştır. Aynı zamanda türbin çarkı üzerinde oluşan kavitasyon miktarlarını da sayısal ortamda azaltarak analiz etmiştir. Lain vd (2010); Francis türbinindeki iç akışı sayısal olarak incelemiştir. Türbin bileşenlerinde meydana gelen enerji kayıpları için zamandan bağımsız, türbin üzerinde meydana gelen dinamik basınç değişimi ve rotor-stator etkileşimleri için de zamana bağlı olmak üzere iki farklı yaklaşım ile hesaplamalı akışkanlar dinamiği prensiplerinin kullanıldığı bir sayısal yaklaşım gerçekleştirilmiştir. Simülasyonlar için ANSYS CFX yazılımı kullanılmıştır. Wang (2012), optimum kanat tasarımı elde etmek için HAD ve CAD yöntemlerini birlikte kullanarak bir simülasyon çalışması gerçekleştirmiştir. Ön tasarımla elde edilen boyutlar esas alınarak CAD ortamında oluşturulan türbin çarkı akış alanında HAD simülasyonlarını gerçekleştirmiştir. Bu simülasyonlarda akış yapısında görülen yerel bozuklukları gidermeye yönelik tasarım değişikliklerini yaparak simülasyonlar tekrarlanmış, hidrolik verimi yüksek, kavitasyon riski düşük kanat yapıları belirlenmiştir.

$\mathrm{Bu}$ çalışmada, küçük ölçekli bir Francis türbinin tüm bileşenlerinin analitik hesapları ve sayısal analizleri gerçekleştirilmiştir. Tasarım için belirlenen net düşü ve debi değerleri $40 \mathrm{~m}$ ve $0,4 \mathrm{~m}^{3} / \mathrm{s}$ 'dir. Tekil kanat Bovet yöntemi ile tasarlanmıştır. Ayar kanat hesabı ise Krivchenko'nun kitabındaki formüller ile tasarlanmıştır (Krivchenko, 1983). ANSYS Bladegen V17.0 ile çark ve ayar kanadı geometrileri oluşturulmuştur. Salyangoz ve Emme borusu geometrileri Solidworks 2013 katı model yazılımı ile oluşturulmuştur. ANSYS CFX V17.0 yazılımı ile sayısal analizler gerçekleştirilmiştir.

\begin{tabular}{|c|c|}
\hline \multicolumn{2}{|l|}{ Terminoloji } \\
\hline$b$ & Ayar kanad yüksekliği $(\mathrm{mm})$ \\
\hline$H$ & Türbin net düşüsü $(m)$ \\
\hline$l$ & $\operatorname{Uzunluk}(m)$ \\
\hline$N$ & Dönme hızl $(\mathrm{rad} / \mathrm{s})$ \\
\hline$n$ & Özgül dönme hızı \\
\hline$R$ & Meridyenel profilin özgül yarıçapı(m) \\
\hline$\dot{V}$ & Hacimsel debi $\left(m^{3} / s\right)$ \\
\hline$v$ & Özgül hacimsel debi $\left(\mathrm{m}^{3} / \mathrm{s}\right)$ \\
\hline$\beta$ & Kanat açısı \\
\hline$\mu$ & Viskozite \\
\hline$D_{g}$ & Ayar kanat merkezinin çapı(m) \\
\hline$L_{q}$ & Ayar kanat eğrilik uzunluğu(m) \\
\hline$t_{g}$ & Ayar kanatları arasındaki dikey mesafe (m) \\
\hline
\end{tabular}

\section{Tasarım}

\section{1. Çark Tasarımı}

Düşü ve debi türbin için nihai tasarımı belirleyici temel unsurlardır. Bu çalışmada, belirlenen bir bölgedeki debi ve düşü verilerine uygun Francis tipi bir hidrolik türbinin tasarımı gerçekleştirilmiştir. Türbin seçiminde debi ve düşü değerleri önemli göstergelerdir. Francis türbinleri yavaş, orta ve yüksek hızlı olarak sınıflandırılır. Bu sınıflandırma özgül hız değerine bağlıdır. Özgül hız değerine bağlı olarak yapılan bu sınıflandırma farklı çark şekillerinin görülmesine neden olur. Farklı özgül hızlar meridyenel profillerin oluşmasını sağlar.

Özgül dönme hızı Bovet (1963) tarafından aşağıdaki formül ile tanımlanmıştır.

$$
\mathrm{n}=\frac{\mathrm{N} \cdot\left(\frac{\dot{\mathrm{v}}}{\pi}\right)^{0,5}}{(2 \mathrm{gH})^{0,75}}
$$

Bovet yöntemine göre n özgül dönme hızı ile çark kanalının şekli tamamen belirlenebilmektedir. Çark kanalının şeklini belirleyen denklemler aşağıda belirtilmiştir (Bovet, 1963). 


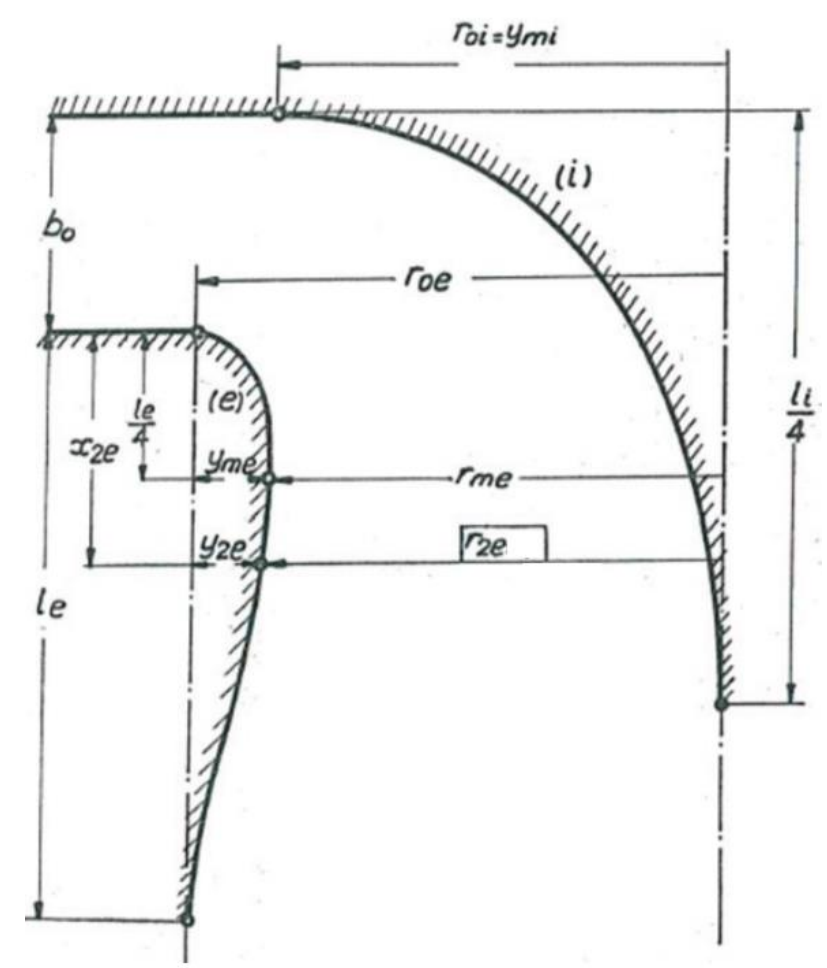

Şekil 2. Çark Kanadı Meridyenel Profili(Bovet, 1963)

$$
\begin{aligned}
& \mathrm{b}_{0}=0,8(2-\mathrm{n}) \mathrm{n} \\
& \mathrm{r}_{0 \mathrm{i}}=\mathrm{y}_{\mathrm{mi}}=0,7+\frac{0,16}{\mathrm{n}+0,08} \\
& \mathrm{r}_{0 \mathrm{e}}=1,255-0,3 \mathrm{n} \\
& \mathrm{l}_{\mathrm{i}}=3,2+3,2(2-\mathrm{n}) \mathrm{n} \\
& \mathrm{l}_{\mathrm{e}}=2,4-1,9(2-\mathrm{n}) \mathrm{n} \\
& \mathrm{y}_{2 \mathrm{e}}=\mathrm{r}_{0 \mathrm{e}}-1 \\
& \mathrm{y}_{\mathrm{me}}=\frac{\mathrm{y}_{2 \mathrm{e}}}{\mathrm{y}_{2 \mathrm{e}} / \mathrm{y}_{\mathrm{me}}} \\
& \mathrm{r}_{\mathrm{me}}=\mathrm{r}_{0 \mathrm{e}}-\mathrm{y}_{\mathrm{me}} \\
& \mathrm{R}_{2 \mathrm{e}}=\left(\frac{\dot{\mathrm{v}}}{\pi} \frac{1}{\mathrm{Nv}_{2 \mathrm{e}}}\right)^{\frac{1}{3}} \\
& \mathrm{R}_{1 \mathrm{i}}=\left(\frac{2 \mathrm{gH}}{\mathrm{N}^{2} \mathrm{~h}_{1 \mathrm{i}}}\right)^{1 / 2}
\end{aligned}
$$



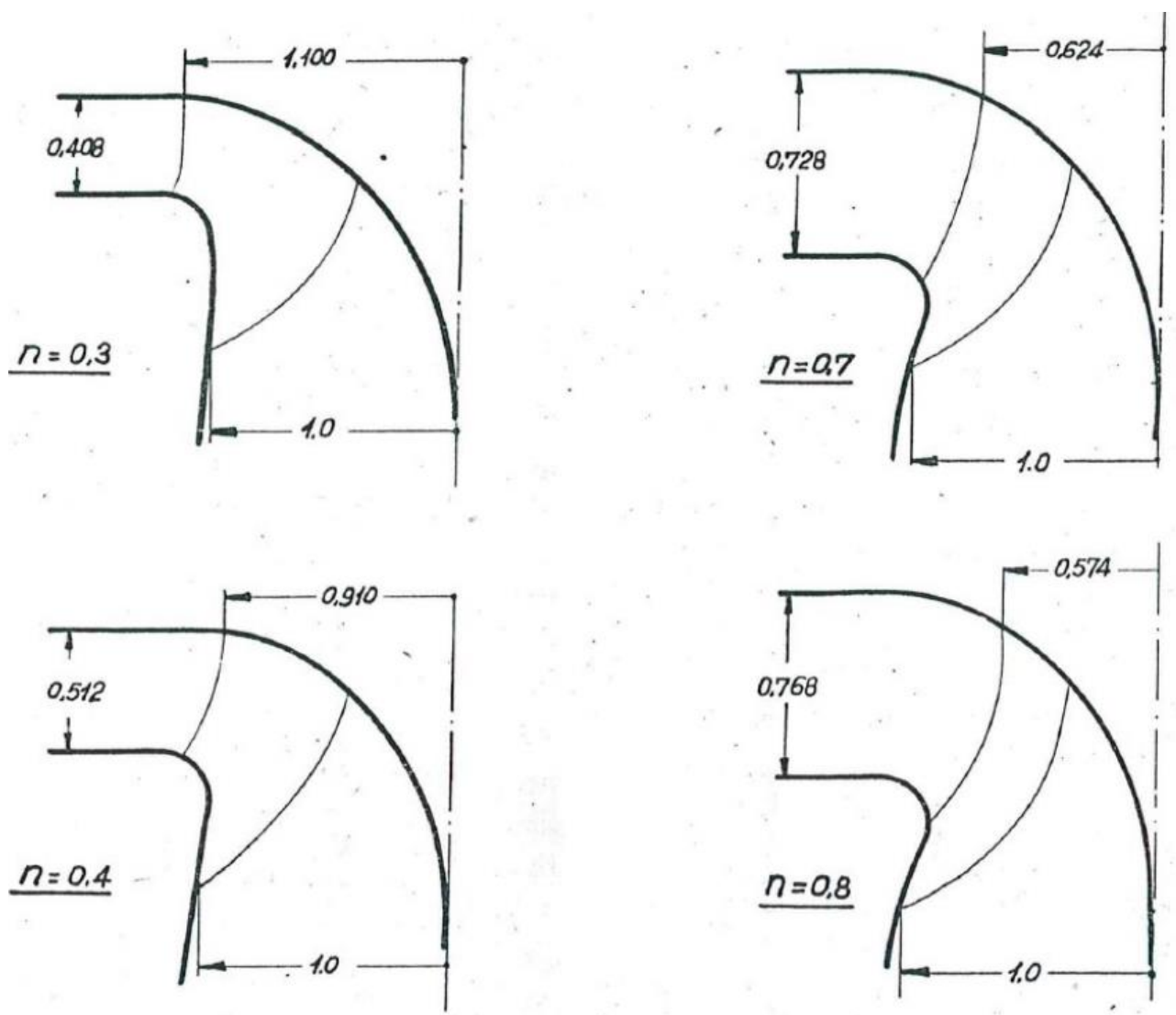

Şekil 3. Özgül Dönme Hızına Göre Çark Kanalı Formunun Değişimi(Bovet, 1963)

Yukarıdaki hesaplar ile çark kanalının giriş ve çıkış noktaları belirlenerek meridyenel profil oluşturulmuş ve çark kanadının iç eğri (hub) ve dış eğri (shroud) ile kesiştiği noktalar belirlenmiştir. Bovet yönteminde, çark kanadı birbirine eşit akış hızlarına sahip akış çizgilerine ayrılmaktadır. Çark kanadı iç eğri (hub) kısmından dış eğri (shroud) kısmına kadar $i, i^{\prime}, i^{\prime \prime}, m, e^{\prime \prime}, e^{\prime}$ ve $e$ isimlerinde olmak üzere toplam 7 akış çizgisine bölünmüştür.

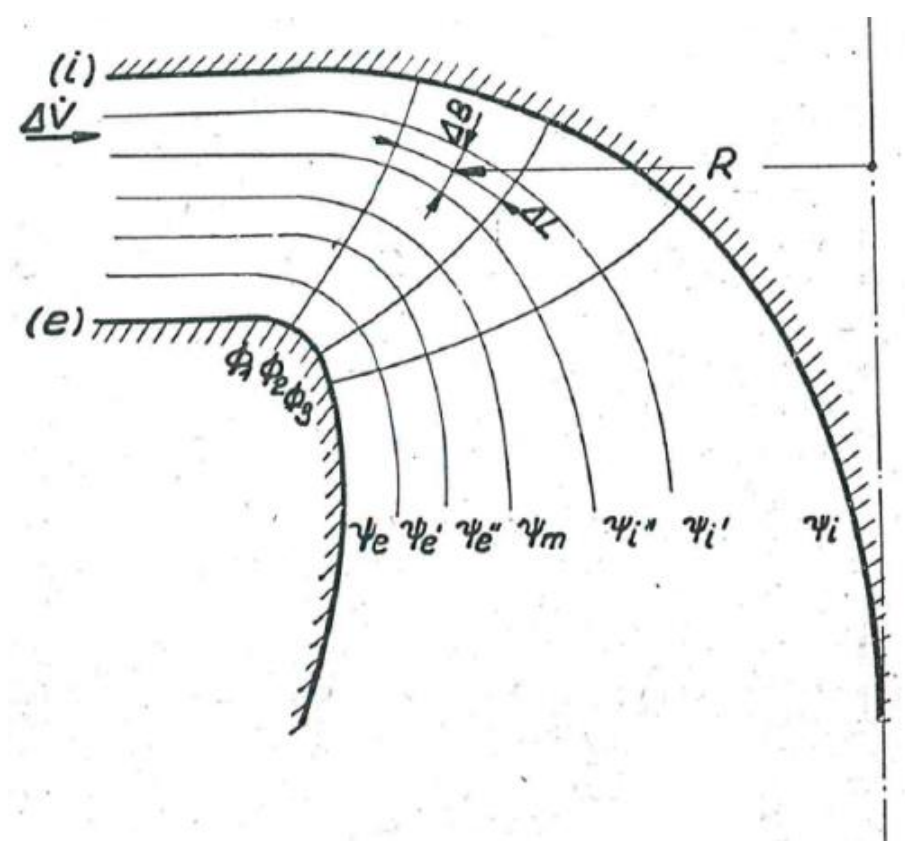

Şekil 4. Meridyenel Profildeki Akış Çizgileri(Bovet, 1963)

$\mathrm{Bu}$ çalışmada belirlenen net düşü ve debi değerleri $40 \mathrm{~m}$ ve $0,4 \mathrm{~m} 3 / \mathrm{s}$ 'dir. Türbin dönme hızı $1500 \mathrm{~d} / \mathrm{dak}$ 'dır. Çark için taahhüt edilen verim \%92'dir. Bu parametreler ile denklem 1'de yerine konduğunda özgül dönme hızı 0,378 olarak elde edilmiştir. Denklem 2'den 11'e kadar elde edilen değerler Tablo 1'de belirtilmiştir. Çark kanalının büyüklüğünü tespit edebilmek için $\mathrm{R}_{2 \mathrm{e}}$ çapını belirlemek yeterlidir. Bu değer denklem 10'dan 144,3 mm olarak elde edilmiştir. 
Tablo 1. Meridyenel Profilden Elde Edilen Değerler

\begin{tabular}{ccc}
\hline Meridyenel Profil Parametreleri & $\begin{array}{c}\text { Boyut } \\
\text { Katsayısı }\end{array}$ & $\begin{array}{c}\text { Gerçek } \\
\text { Boyut(mm) }\end{array}$ \\
\hline$b_{0}$ & 0,49 & 73,5 \\
$r_{0 i}=y_{m i}$ & 1,049 & 157,35 \\
$r_{0 e}$ & 1,1416 & 171,24 \\
$l_{i}$ & 5,1619 & 774,285 \\
$l_{e}$ & 1,235 & 185,25 \\
$y_{2 e}$ & 0,1416 & 21,24 \\
$y_{m e}$ & 0,1575 & 23,625 \\
$r_{m e}$ & 0,9841 & 174,615 \\
$\mathrm{x}_{2 \mathrm{e}}$ & 0,5 & 75 \\
\hline
\end{tabular}

Bu hesaplardan sonra belirlenen 7 akış çizgisi için giriş ve çıkış kenarlarının yarıçapları ve açıları Tablo 2'de verilmiştir.

Tablo 2. Akış Çizgilerinin Giriş Ve Çıkııs Kenarlarındaki Yarıçapları Ve Açıları

\begin{tabular}{ccccc} 
Akıs çizgileri & $\mathbf{R}_{\mathbf{1}}(\mathbf{m m})$ & $\boldsymbol{\beta}_{\mathbf{1}}$ & $\mathbf{R}_{\mathbf{2}}(\mathbf{m m})$ & $\boldsymbol{\beta}_{\mathbf{2}}$ \\
\hline i & 136,00 & 60,81 & 62.95 & 34,91 \\
i' & 136,11 & 60,61 & 70,67 & 30,65 \\
i', & 136,33 & 60,21 & 83,57 & 25,54 \\
m & 136,82 & 59,34 & 101,01 & 20,89 \\
e', & 138,91 & 55,85 & 117,54 & 17,85 \\
e' & 142,92 & 49,98 & 131,92 & 15,85 \\
e & 149,29 & 42,59 & 144,30 & 14,46 \\
& & & & \\
\hline
\end{tabular}

\subsection{Ayar Kanatları Tasarımı}

Ayar kanatları, eksenleri etrafında dönerek çark etrafındaki akışın dağıtılmasını ve türbine gelen akışın hızının ayarlanmasını sağlamaktadır.

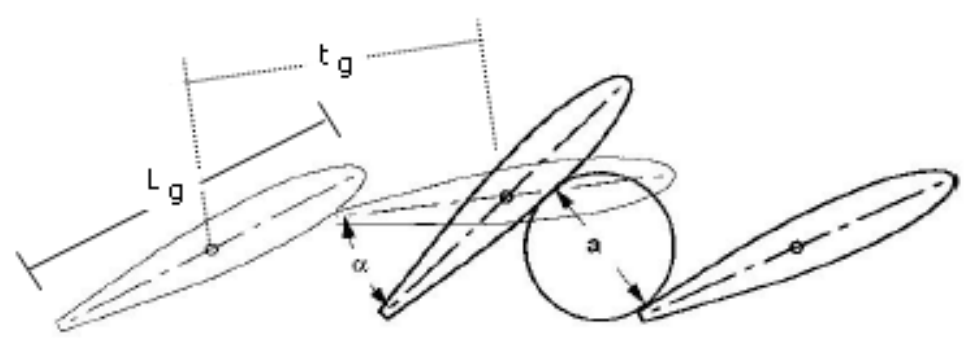

Şekil 5. Ayar Kanadi (ESHA, 2004) 
Ayar kanadı çapı $\mathrm{D}_{\mathrm{g}}$ genelde çark giriş çapının 1,16 katı olarak seçilir. Ayar kanat çapı belirlendikten sonra, ayar kanat sayısı belirlenir. Genelde 12,16 veya 24 seçilir. Su geçişine izin vermeyecek ve kapalı pozisyonda üst üste binecek şekilde ayar kanat uzunluğu hesaplanır. Genel kabul görmüş kural olarak aşağıdaki denklemler uygulanır (Krivchenko, 1983).

$$
\mathrm{L} / \mathrm{t}_{\mathrm{g}}=1,1
$$

Kapalı konumda \%10 üstüne binme durumundaki ayar kanat uzunluğu;

$$
\begin{aligned}
& \mathrm{L}_{\mathrm{g}}=\frac{\pi \mathrm{D}_{\mathrm{g}}}{\text { ayar kanatları sayısı }} \frac{1}{0,9} \\
& \mathrm{t}_{\mathrm{g}} \approx \frac{\pi \mathrm{D}_{\mathrm{g}}}{\text { ayar kanatları sayısı }}
\end{aligned}
$$

Normal çalışma rejiminde ayar kanatları doğrultu açısı (Bovet, 1963);

$$
\tan \alpha_{0}=\frac{1}{\pi B_{0} h_{i}} \frac{N \dot{V}}{2 g H}
$$

Ayar kanat sayısı 16 olarak belirlenmiştir. Denklem 12-15 hesaplandığında Tablo 3'deki değerler elde edilmiştir.

Tablo 3. Ayar Kanat Ölçüleri Ve Doğrultu Açısı

\begin{tabular}{cccc}
\hline $\mathbf{D}_{\mathbf{g}}(\mathbf{m m})$ & $\mathbf{L}_{\mathbf{g}}(\mathbf{m m})$ & $\mathbf{t}_{\mathbf{g}}(\mathbf{m m})$ & $\boldsymbol{\alpha}_{\mathbf{0}}$ \\
\hline 157,76 & 34,42 & 31,29 & 19,98
\end{tabular}

\subsection{Salyangoz Tasarımı}

Salyangoz içindeki suyun, salyangozun her kesitine eşit ve sabit bir değerde dağılması gerekir. Cebri borudan gelen suyu, sabit ve ayar kanatlarına dağıtabilmesi için salyangoz sabit kanatların çevresine sarılır.

Salyangoz içerisindeki hız (Ergin, 1972);

$$
\mathrm{C}=\mathrm{k} \sqrt{2 \mathrm{gH}_{\mathrm{d}}} ; \mathrm{k}=0,2-0,3
$$

Salyangoz kesit hesabı (Ergin, 1972);

$$
\dot{\mathrm{V}}=\frac{\pi \mathrm{d}_{\mathrm{s}}^{2}}{4} \mathrm{C}
$$

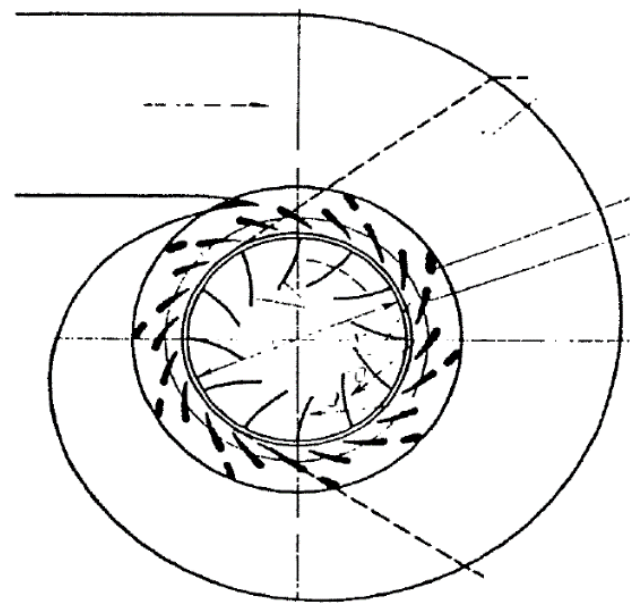

Şekil 6. Salyangoz Görünümü (Krivchenko, 1986) 
Denklem 16 ve 17 kullanılarak tablodaki değerler elde edilmiştir.

Tablo 4. Salyangoz Kesit Ölçüleri Ve Debileri

\begin{tabular}{cccc}
\hline $\begin{array}{c}\text { Kesit } \\
\text { Sayısı }\end{array}$ & $\begin{array}{c}\text { Debi } \\
\text { dağılımı }\end{array}$ & Debi $\left(\mathbf{m}^{3} / \mathbf{s}\right)$ & $\begin{array}{c}\text { Salyangoz Kesit Çapı } \\
\boldsymbol{d}_{\boldsymbol{s}}(\mathbf{m})\end{array}$ \\
\hline 1 & $16 / 16$ & 0,4 & 0,24623 \\
2 & $15 / 16$ & 0,375 & 0,23841 \\
3 & $14 / 16$ & 0,35 & 0,23032 \\
4 & $13 / 16$ & 0,325 & 0,22195 \\
5 & $12 / 16$ & 0,3 & 0,21324 \\
6 & $11 / 16$ & 0,275 & 0,20416 \\
7 & $10 / 16$ & 0,25 & 0,19466 \\
8 & $9 / 16$ & 0,225 & 0,18467 \\
9 & $8 / 16$ & 0,2 & 0,17411 \\
10 & $7 / 16$ & 0,175 & 0,16286 \\
11 & $6 / 16$ & 0,15 & 0,15078 \\
12 & $5 / 16$ & 0,125 & 0,13764 \\
13 & $4 / 16$ & 0,1 & 0,12311 \\
14 & $3 / 16$ & 0,075 & 0,10662 \\
15 & $2 / 16$ & 0,05 & 0,08705 \\
16 & $1 / 16$ & 0,025 & 0,06155
\end{tabular}

\subsection{Emme Borusu Tasarımı}

Emme borusu tasarımındaki dikkate alınması gereken en önemli parametre geri kazanım oranıdır. Geri kazanım oranı aracılığıyla suyun sahip olduğu kinetik enerjinin ne kadarının basınca dönüştüğü ifade edilmektedir. Emme borusunun şematik yapısı şekilde verilmiştir. Emme borusu giriş çapı çark çıkış çapına eşit alınmıştır. $H_{1}, H_{2}, H_{3}, H_{4}, \theta_{1}$ ve $\theta_{2}$ parametreleri değiştirilerek geri kazanım oranı yüksek bir emme borusu tasarımı hedeflenmiştir. Küçük türbinlerde emme borusu genelde dairesel kesitli konik borulardan imal edilmektedir. Koni açısının büyük olması daha fazla enerji toplanmasını sağlamaktadır. Emme borusunun çok fazla uzun olmaması için genelde dirsek kullanımı tercih edilmektedir (Ergin, 1972).

$$
C_{P}=\frac{P_{c ̧ l k l s \grave{s}}-P_{\text {giris }}}{\frac{\rho V^{2}}{2 g}}
$$

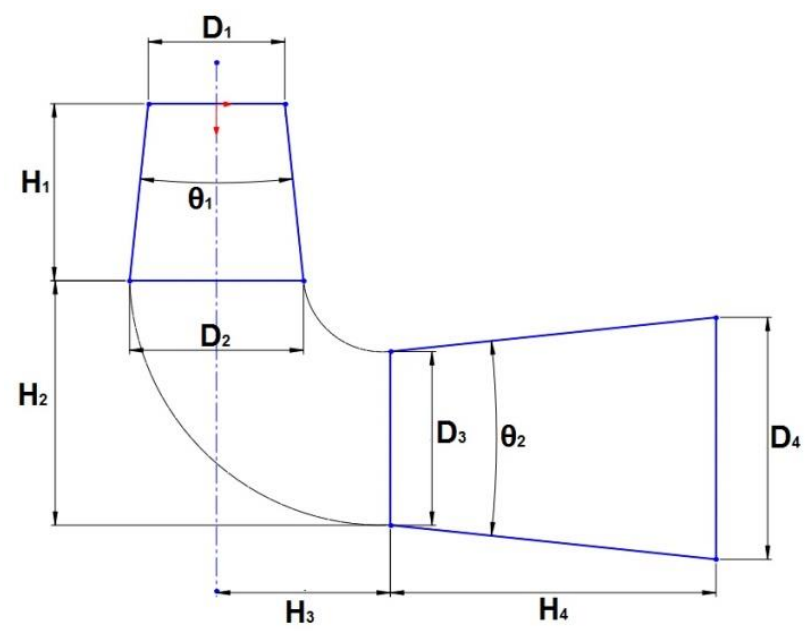

Şekil 7. Emme Borusu Şekli Ve Tasarım Parametreleri 
Tablo 5. Emme Borusunda Değiştirilen Parametrelerin Geri Kazanım Oranına Etkisi

$\begin{array}{ccc}\text { Değiştirilen Parametreler } & \text { Sonuç } & \text { Geri Kazanım } \\ \text { Oranı }\end{array}$

$\mathbf{H}_{4}, \mathbf{D}_{\mathbf{4}}$ ve $\boldsymbol{\theta}_{\mathbf{2}}$ değerleri azaltıldı.

$\boldsymbol{\theta}_{2}$ açısı arttırıldı.

$\mathbf{H}_{1}$ ve $\boldsymbol{\theta}_{2}$ arttırildi.

$\boldsymbol{\theta}_{2}$ açısı biraz daha arttırıldı.

$\boldsymbol{\theta}_{2}$ açısı azaltıldı
Akış çizgilerindeki ayrışma ve basınç dağılımı değişmedi. Geri kazanım oranı azaldı.

Akış çizgilerindeki ayrışma ve basınç dağılımı değişmedi. Geri kazanım oranı arttı.

Akış çizgilerindeki ayrışma azaldı ve basınç dağılımı düzeldi. Geri kazanım oranı arttı.

Akış çizgileri emme borusu çıkışında bozuldu. Basınç dağılımı bozuldu. Geri kazanım oranı azaldı.

Akış çizgilerinin emme borusu çıkışındaki bozulması azaldı. Geri kazanım oranı azaldı.
0,7557

0,80223

Emme borusu için yapılan optimizasyon çalışması sonucu elde edilen maksimum geri kazanım oranı 0,81188'dir. Bu değer doğrultusunda ortaya çıkan emme borusu nihai tasarım parametreleri aşağıdaki tabloda verilmiştir.

Tablo 6. Emme Borusu Nihai Tasarım Parametreleri

\begin{tabular}{cc}
\hline $\begin{array}{c}\text { Tasarım } \\
\text { Parametreleri }\end{array}$ & Boyut \\
\hline $\mathbf{D}_{\mathbf{1}}$ & $288,6 \mathrm{~mm}$ \\
$\mathbf{D}_{\mathbf{2}}$ & $367,36 \mathrm{~mm}$ \\
$\mathbf{D}_{\mathbf{3}}$ & $367,36 \mathrm{~mm}$ \\
$\mathbf{D}_{\mathbf{4}}$ & $494,15 \mathrm{~mm}$ \\
$\mathbf{H}_{\mathbf{1}}$ & $374,675 \mathrm{~mm}$ \\
$\mathbf{H}_{\mathbf{2}}$ & $517,17 \mathrm{~mm}$ \\
$\mathbf{H}_{\mathbf{3}}$ & $367,36 \mathrm{~mm}$ \\
$\mathbf{H}_{\mathbf{4}}$ & $688,36 \mathrm{~mm}$ \\
$\boldsymbol{\theta}_{\mathbf{1}}$ & $12^{\circ}$ \\
$\boldsymbol{\theta}_{\mathbf{2}}$ & $12^{\circ}$
\end{tabular}

\section{Sayısal Analiz}

Tüm türbinin hidrolik verimi için HAD analizleri gerçekleştirmeden önce türbin bileşenlerinin sırasıyla HAD analizleri gerçekleştirilmiştir. Öncelikle çark kanadı verimliliği için sayısal analizler gerçekleştirilmiştir. Kanat üzerindeki basınç dağılımları ve akış çizgileri tespit edilmiştir. Daha sonra, ayar kanatları, salyangoz ve emme borusu için HAD analizleri gerçekleştirilmiştir. Çark kanadı ve ayar kanadı geometrileri ANSYS Bladegen V17.0'da oluşturuldu. Oluşturulan kanat geometrilerinin ANSYS Turbogrid V17.0 modulü ile ağ yapıları oluşturulmuştur.

Literatürdeki çalışmalarda k- $\varepsilon$ türbülans modeli yaygın olarak kullanılmaktadır. Literatürdeki deneysel verilerle doğrulanmış pek

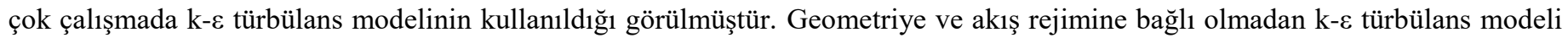
ile başarılı sonuçlar alınabilmektedir. HAD analizleri için akışkan olan su tek fazlı ve sıkıştırılamaz olarak seçilmiştir. Analizler kararlı hal için gerçekleştirilmiştir. ANSYS CFX Solver Guide'da belirtilen temel denklemler kullanılmıştır(CFX Solver Theory Guide, 2013).

Süreklilik denklemi;

$$
\frac{\partial \rho}{\partial t}+\frac{\partial\left(\rho U_{j}\right)}{\partial x_{j}}=0
$$

Momentum Denklemi;

$$
\frac{\partial\left(\rho U_{i}\right)}{\partial t}+\frac{\partial\left(\rho U_{j} U_{i}\right)}{\partial x_{j}}=-\frac{\partial p^{\prime}}{\partial x_{i}}+\frac{\partial}{\partial x_{j}}\left[\mu_{e f f}\left(\frac{\partial U_{i}}{\partial x_{j}}+\frac{\partial U_{j}}{\partial x_{i}}\right)\right]+S_{M}
$$

Türbülans kinetik enerji ve dağılım oranı için k ve $\varepsilon$ değerleri aşağıdaki diferansiyel denklemlerden gelmektedir.

$$
\begin{aligned}
& \frac{\partial(\rho k)}{\partial t}+\frac{\partial\left(\rho U_{j} k\right)}{\partial x_{j}}=\frac{\partial}{\partial x_{j}}\left[\left(\mu+\frac{\mu_{t}}{\sigma_{k}}\right) \frac{\partial k}{\partial x_{j}}\right]+P_{k}-\rho \varepsilon+P_{k b} \\
& \frac{\partial(\rho \varepsilon)}{\partial t}+\frac{\partial\left(\rho U_{j} \varepsilon\right)}{\partial x_{j}}=\frac{\partial}{\partial x_{j}}\left[\left(\mu+\frac{\mu_{t}}{\sigma_{\varepsilon}}\right) \frac{\partial \varepsilon}{\partial x_{j}}\right]+\frac{\varepsilon}{k}\left[C_{\varepsilon 1} P_{\varepsilon}-C_{\varepsilon 2} \rho \varepsilon+C_{\varepsilon 3} P_{\varepsilon b}\right]
\end{aligned}
$$


Tüm türbin ve bileşenleri için yapılan HAD analizlerinde giriş sınır şartı toplam basınç, çıkış sınır şartı kütlesel debi olarak ayarlanmıştır. Çark analizlerinde akış hacminin yan duvarları için dönme periyodik olarak düzenlenmiştir. İç eğri, dış eğri ve kanat yüzeyleri için kaymaz duvar sınır koşulları olarak kabul edilmiştir. HAD analizlerinde ANSYS CFX modülünün 'Turbo mode' özelliği kullanılarak gerçekleştirilmiştir.

\section{Analiz Sonuçları}

Yapılan HAD çalışmalarının sonuçları bu başlıkta sunulmuştur. Elde edilen sonuçlarda mutlak basınç, akış çizgileri gibi değerler de dikkatle incelenmiştir. Yüksek verim değerleri elde edebilmek için kanat üzerindeki basıncın kademeli olarak azalması gerekmektedir.

İlk olarak analizlere tasarımı tamamlanmış olan çark ile başlanmıştır. HAD analizleri sonucunda elde edilen ilk çark verimi \%86,6 olmuştur.
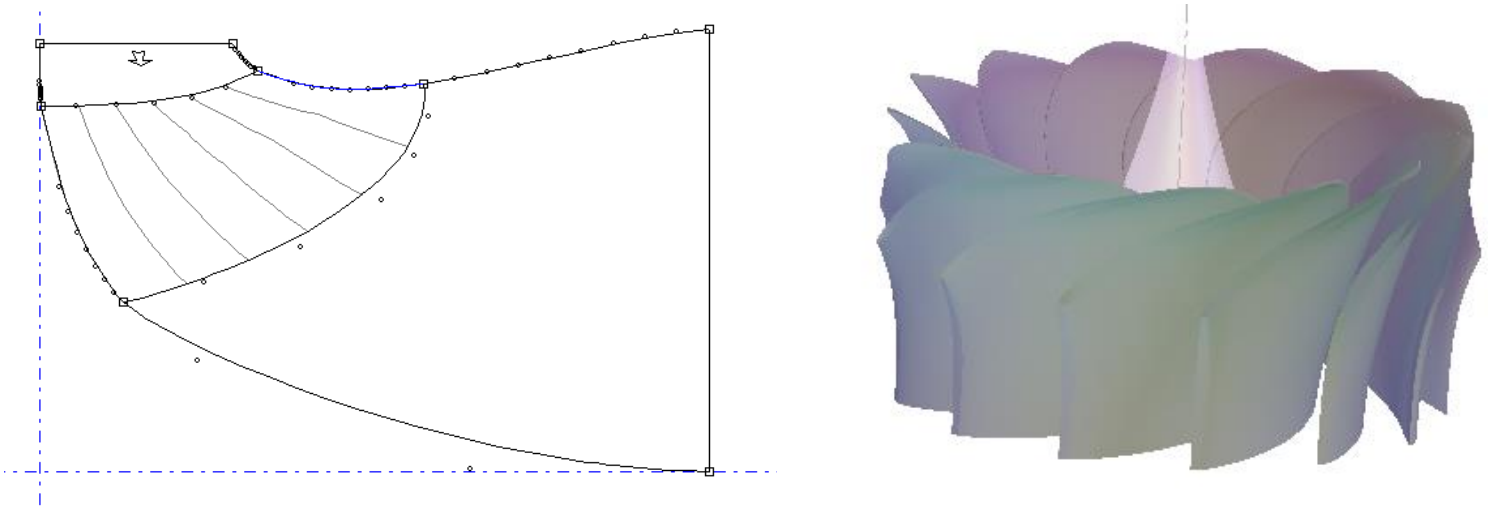

Şekil 8. İlk Çark İçin BladeGen'de Oluşturulan Meridyenel Profil

Kanat üzerindeki akım çizgilerinin açıları ve konumları değiştirilerek farklı kanat profilleri elde edilmiştir. Elde edilen farklı kanat profilleri için analizler gerçekleştirilerek çark verimindeki değişimler gözlemlenmiştir.

a)

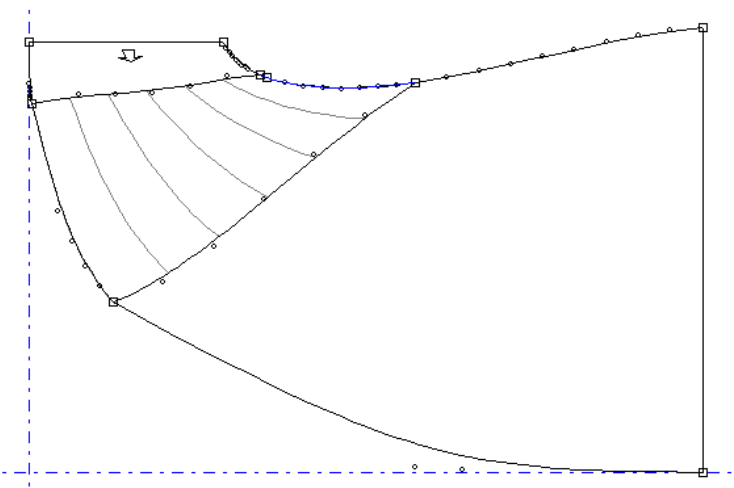

b)

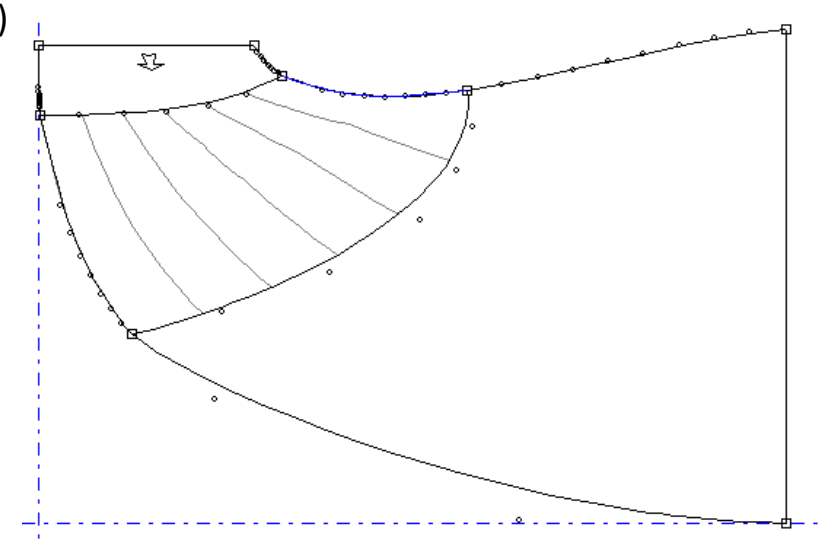

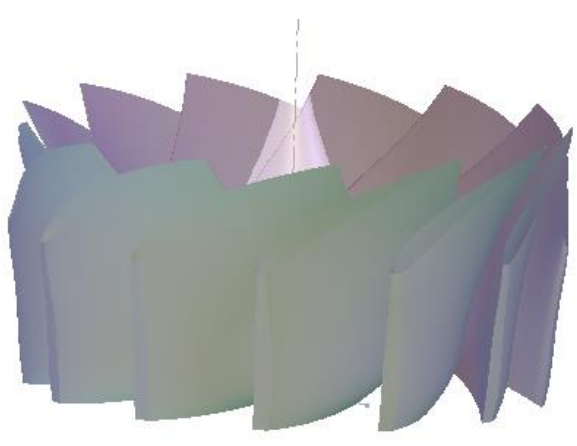

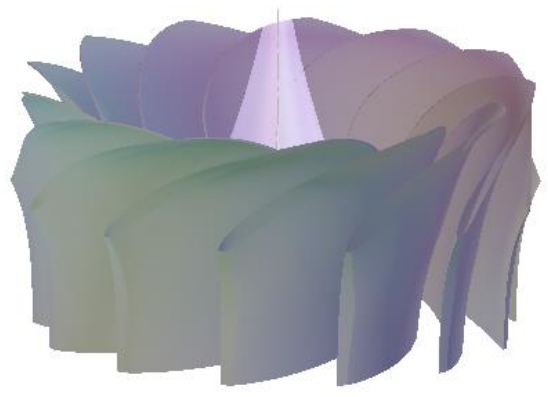

Şekil 9. Akım Çizgilerinin Açıları Ve Konumları Değiştirilerek Elde Edilen Kanat Meridyenel Profillerinden Örnekler a) \%87 Verim Elde Edilen Kanat Meridyenel Profili; b) \%89 Verim Elde Edilen Kanat Meridyenel Profili 
Elde edilen kanat profillerinde yapılan analizlerin sonrasında, kanat üzerindeki akış hacminin artmasının verime pozitif etkisinin olduğu görülmüştür. Kanat üzerindeki akım çizgilerine ait hücum açılarının artmasının da aynı şekilde verime pozitif etkisinin olduğu görülmüştür. Bu gözlemler sonucunda nihai kanat meridyenel profili oluşturulmuştur ve çark analizleri gerçekleştirilmiştir. \%91,52 verim değerine sahip çark kanadı meridyenel profili elde edilmiştir.
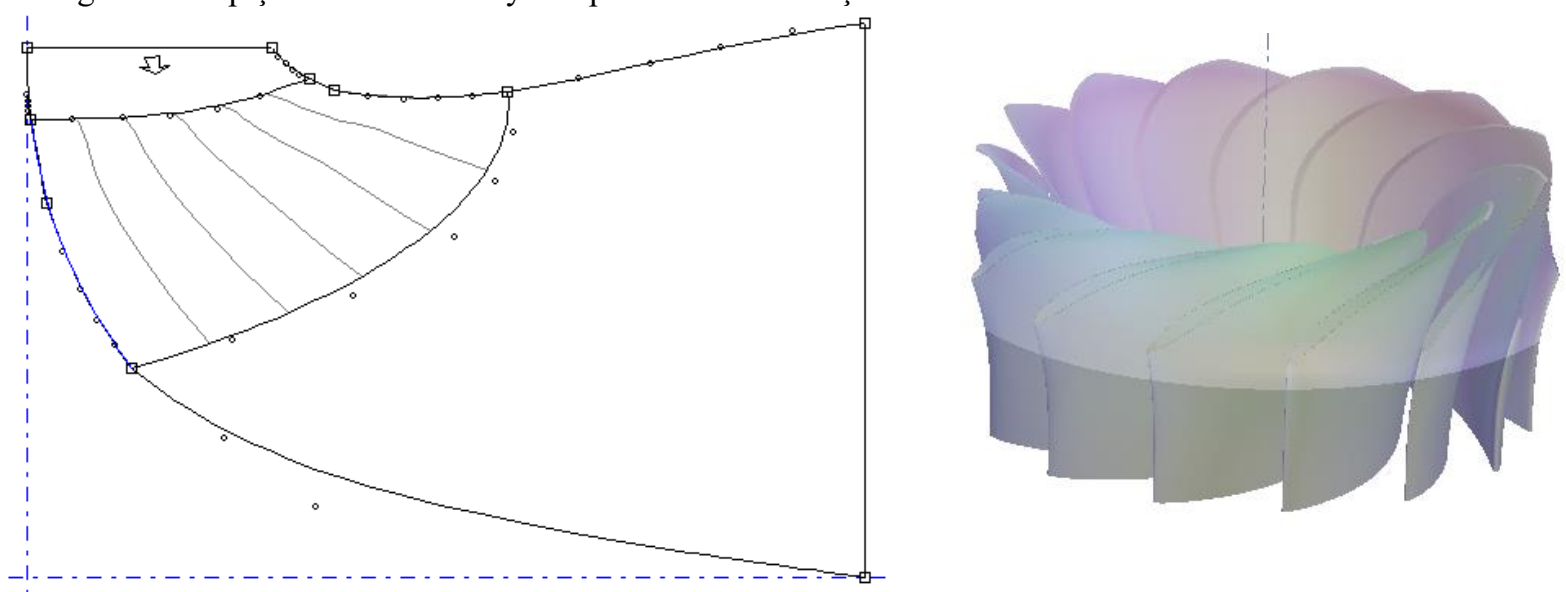

Şekil 10. \%91,52 Verim Değerine Sahip Kanat Meridyenel Profili

a)

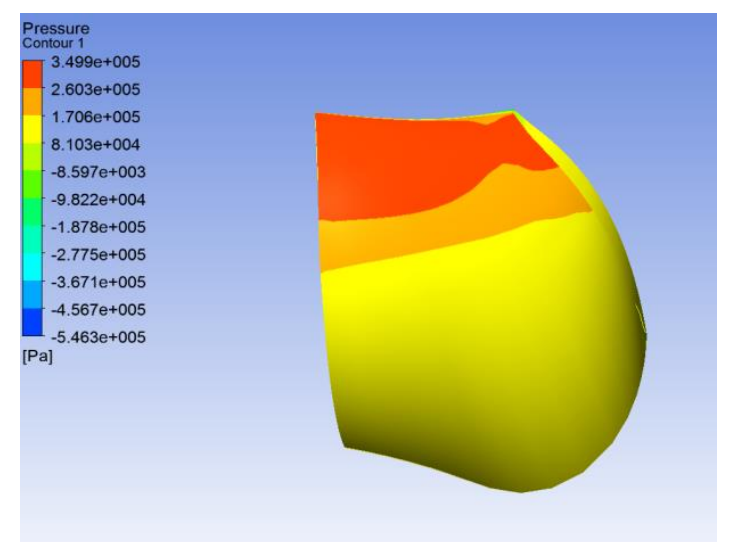

b)

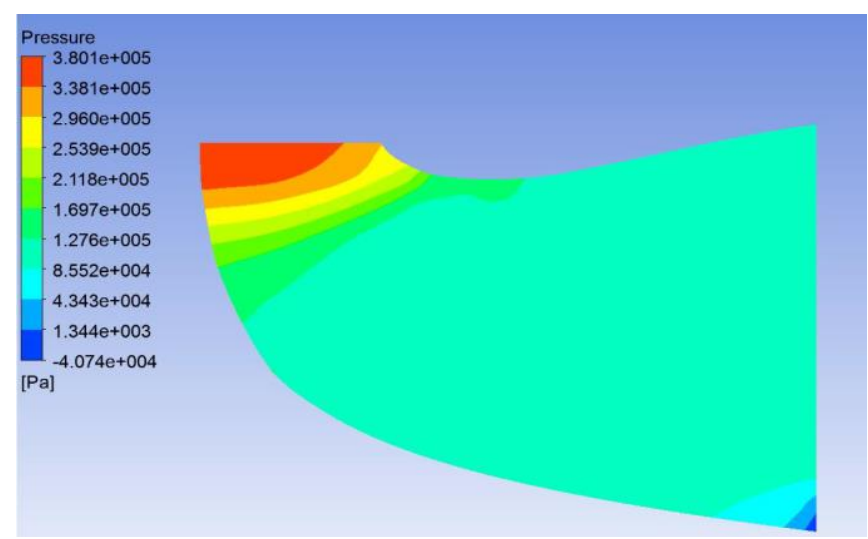

Şekil 11. Çark Kanadı a) Basınç Dağglımı; b) Meridyenel Profildeki Basınç Dağılımı

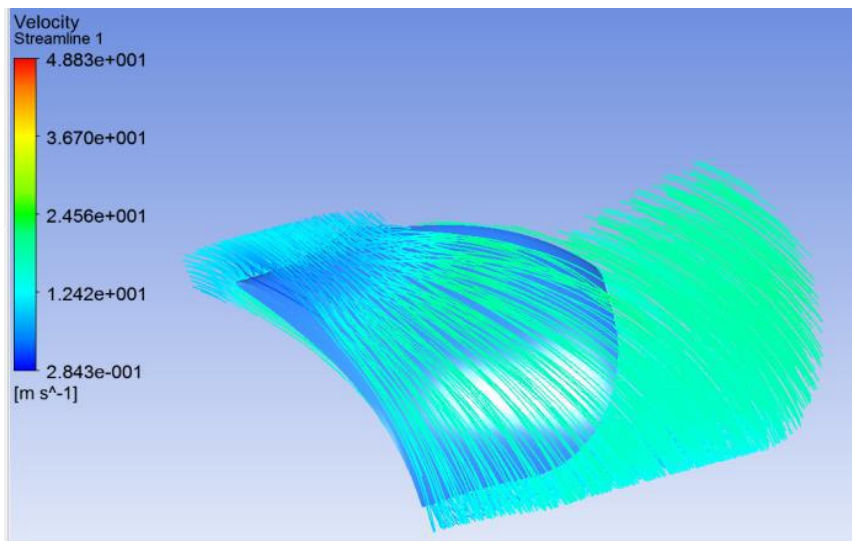

Şekil 12. Kanat Yüzeyindeki Akış Dağılımı 


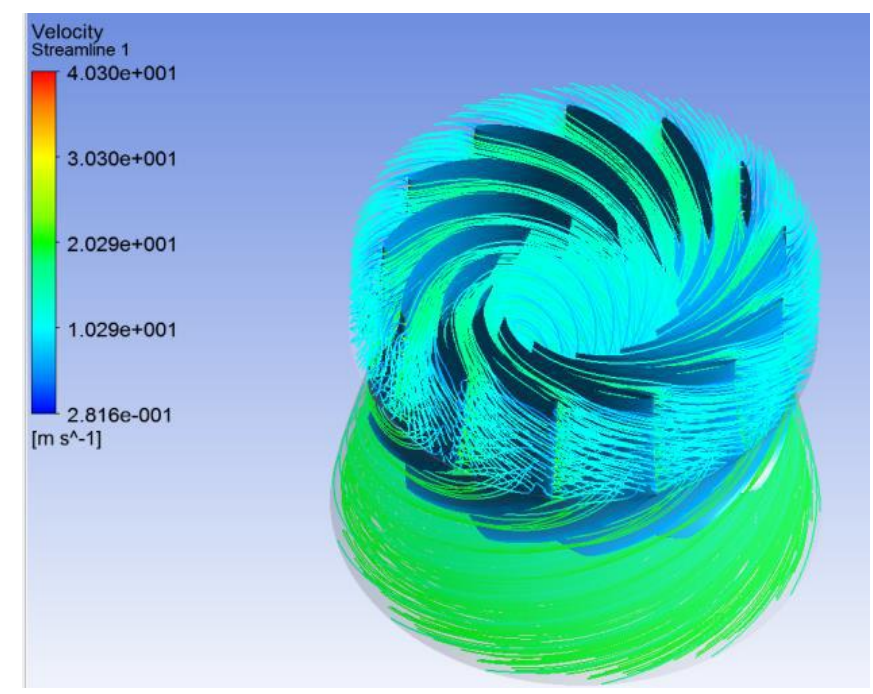

Şekil 13. Çark Akış Dağılımı

Çark analizleri tamamlandıktan sonra tasarımı tamamlanan ayar kanatları, salyangoz ve emme borusu için analizler gerçekleştirilmiştir.
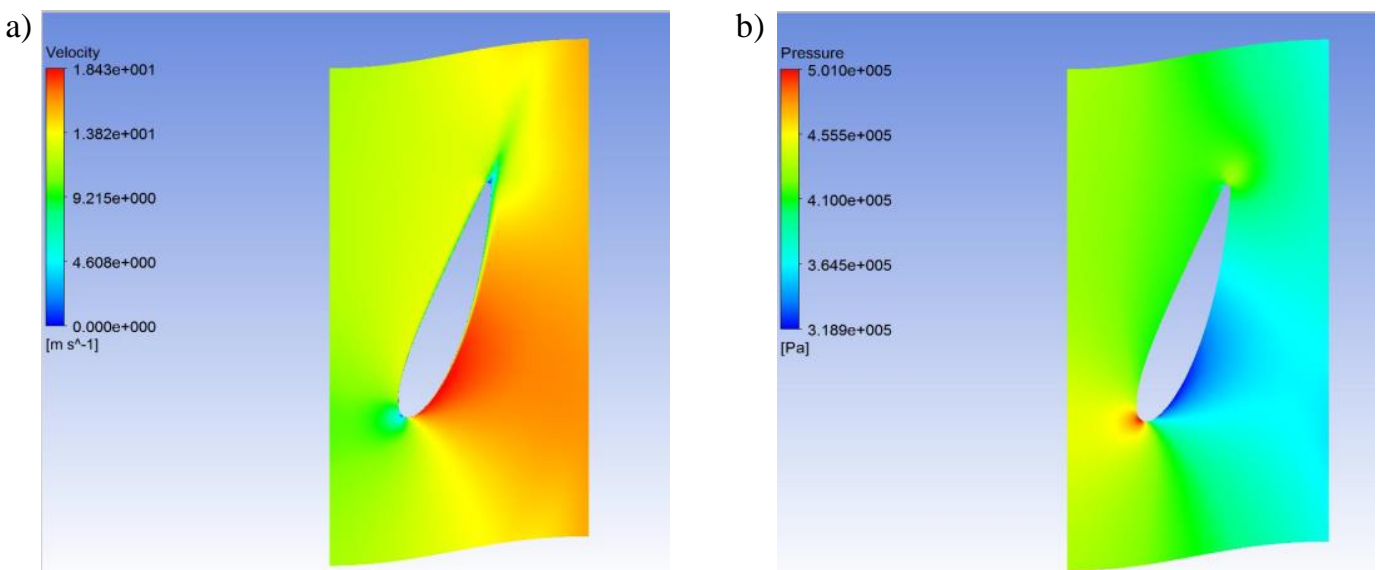

Şekil 14. Ayar Kanadı a) Hız Dağılımı; b) Basınç Dağılımı

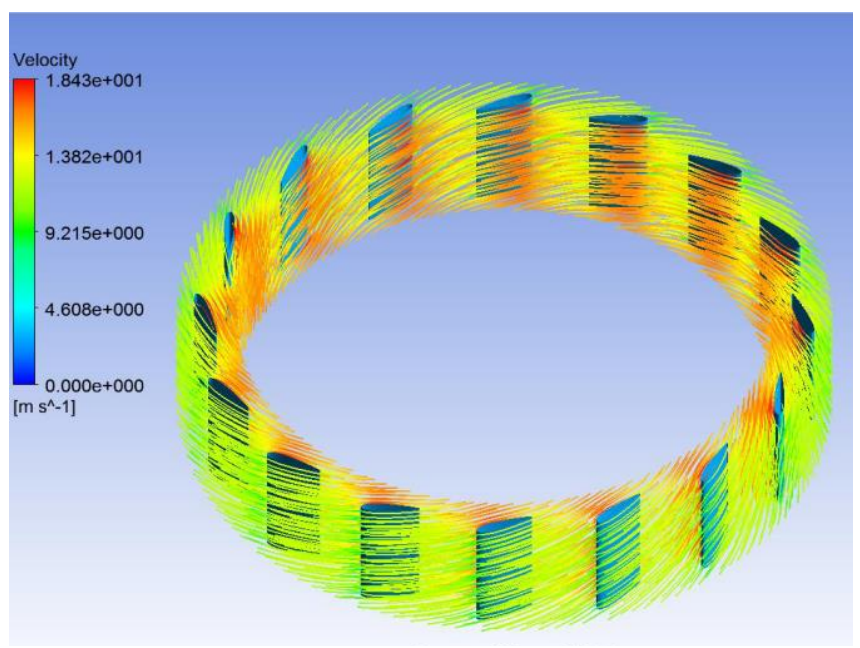

Şekil 15. Ayar Kanatları Hız dağılımı 


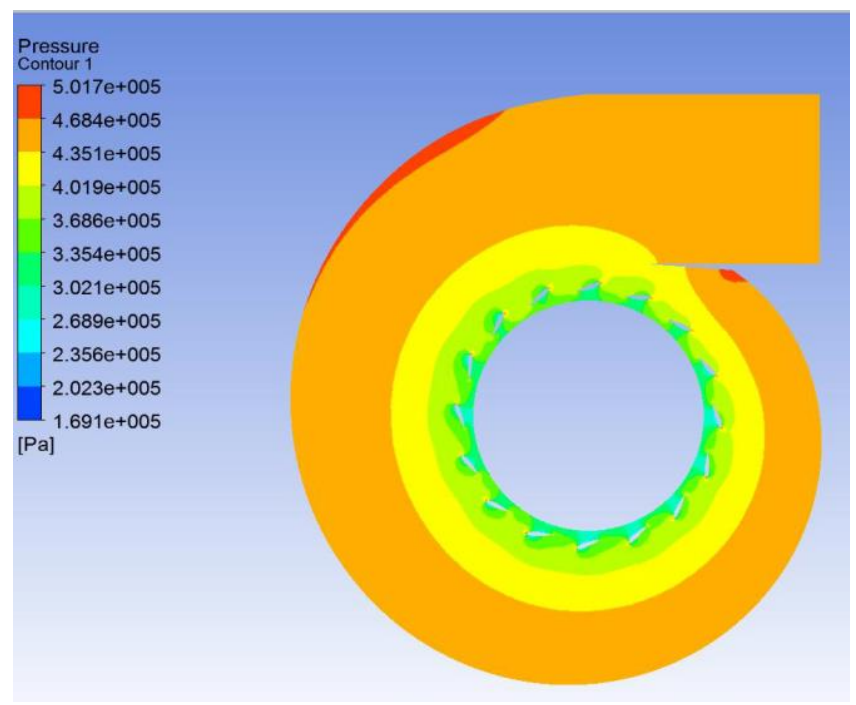

Şekil 16. Salyangoz Ve Ayar Kanatları Basınç Dağılımı

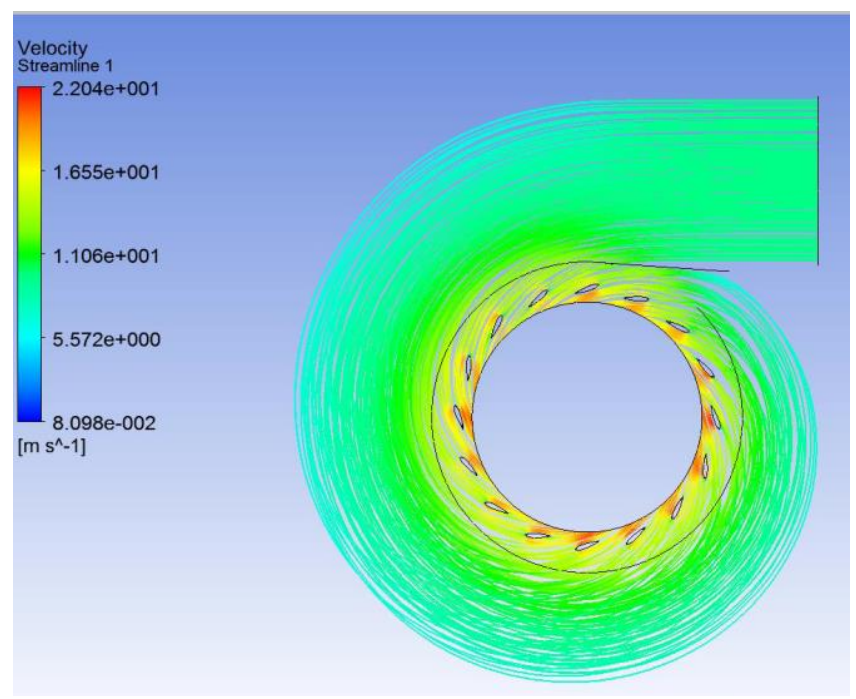

Şekil 17. Salyangoz Ve Ayar Kanatları Hız Dağılımı

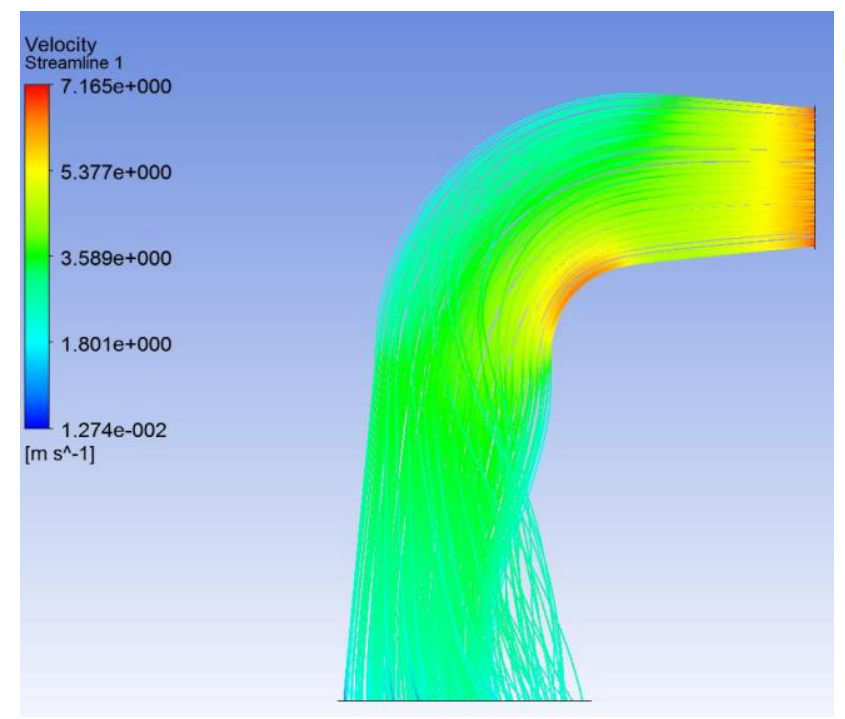

Şekil 18. Emme Borusu Hız Dağılımı 


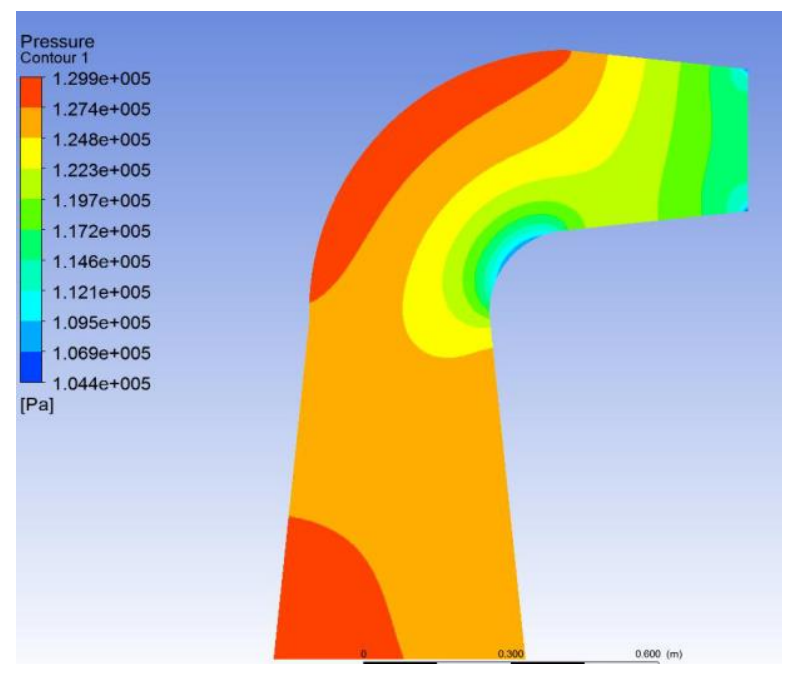

Şekil 19. Emme Borusu Basınç Dağılımı

Çark kanadındaki basınç dağılımı incelendiğinde meridyenel düzlemde kanadın basınç değişimi beklendiği gibi gerçekleşmiştir. Kanat üzerinde herhangi bir ayrılma olmadan akışın ilerlediği görülmüştür. Böylece akışkan momentum transferi artmakta akışkan gücü kanat aracılığı ile türbine aktarılabilmektedir. Akışın ayrılma olmadan ilerlemesi yüksek verim elde etmek için önemli bir kriterdir. Akışkanın potansiyel enerjisini doğru bir şekilde çarka aktarmak için akışın kanat üzerinde ayrılmadan ilerlemesi gerekir. Çark üzerindeki akış çizgileri incelendiğinde kanadın çıkış tarafındaki hızın giriş tarafından daha hızlı olduğu görülmektedir. Basıncın kademeli düşmesinin sonucu olarak girişten çıkışa hız dağılımının düzgün bir şekilde geçiş yaptığı görülmektedir.

Türbin bileşenlerinin analizleri tamamlandıktan sonra mesh atılmış bileşenlerin montajı yapılmıştır ve tüm türbin için analizler gerçekleştirilmiş̧ir. Analizde kullanılan ağ yapısı, ayarlar ve sınır şartları aşağıdaki tablolarda verilmiş̧ir.

Tablo 7. Tüm Türbin Analizleri İçin Oluşturulan Ağ Yapısı

\begin{tabular}{cccc}
\hline Eleman Sayıs1 & $\begin{array}{c}\text { Dört yüzlü } \\
\text { Eleman Sayıs1 }\end{array}$ & $\begin{array}{c}\text { Alt1 yüzlü } \\
\text { Eleman Sayıs1 }\end{array}$ & $\begin{array}{c}\text { A } ّ \\
\text { Say1s1 }\end{array}$ \\
\hline 8847154 & 4483730 & 4363424 & 5588141
\end{tabular}

Tablo 8. Tüm Türbin Analizleri İçin Kullanılan Önemli Sınır Şartları

\begin{tabular}{ccccccc}
\hline Türbülans Modeli & Duvar sürtünmesi & Referans basınç & Akışkan & $\begin{array}{c}\text { Salyangoz giriş } \\
\text { sinır şartı }\end{array}$ & $\begin{array}{c}\text { Emme borusu } \\
\text { çıkıs sınır şartı }\end{array}$ & Çark dönme hızı \\
\hline k- $\varepsilon$ modeli & $\begin{array}{c}\text { Sürtünmesiz } \\
\text { Duvar }\end{array}$ & $0[\mathrm{~Pa}]$ & $\mathrm{Su}$ & $493725[\mathrm{~Pa}]$ & $400[\mathrm{~kg} / \mathrm{s}]$ & $1500[\mathrm{~d} / \mathrm{dk}]$
\end{tabular}

Tablo 9. Tüm Türbin Analizleri İçin Kullanılan Etki Alanları Arasındaki Ara Yüzler

\begin{tabular}{cc}
\hline Bağlant1 & Değişen Çerçeve Modeli \\
\hline GGI & Frozen Rotor
\end{tabular}

Tablo 10. Tüm Türbin Analizleri İçin Kullanılan Çözüm Şartları

\begin{tabular}{cccc}
\hline Adveksiyon Şeması & Sayısal Türbülans & Yakınsama Hedefi & Yakınsama Tipi \\
\hline Yüksek Çözünürlük & Yüksek Mertebe & $10^{-6}$ & RMS
\end{tabular}

Türbine ait sayısal analiz sonuçları incelendiğinde; akış çizgilerinin salyangoz girişinden başlayarak bozulma gerçekleşmeden türbin boyunca ilerlediği, salyangozdaki yüksek basıncın ayar kanatları ve çark bölgesine ilerledikçe kademeli olarak azaldığı, akış hızının kanadın çıkış tarafında giriş tarafına göre daha hızlı olduğu ve çark kanatları üzerindeki basınç dağılımının kademeli olarak azaldığı görülmektedir. 


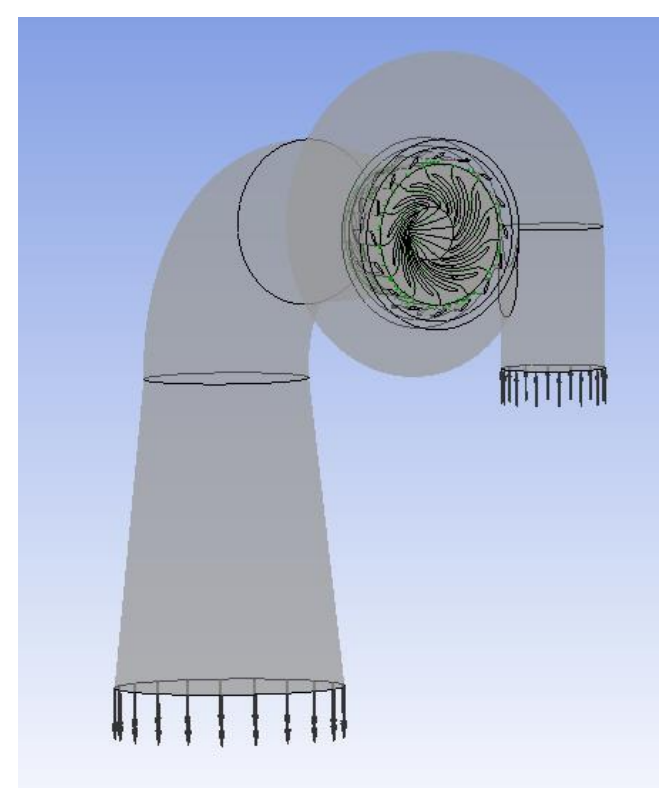

Şekil 20. Türbin HAD Modeli

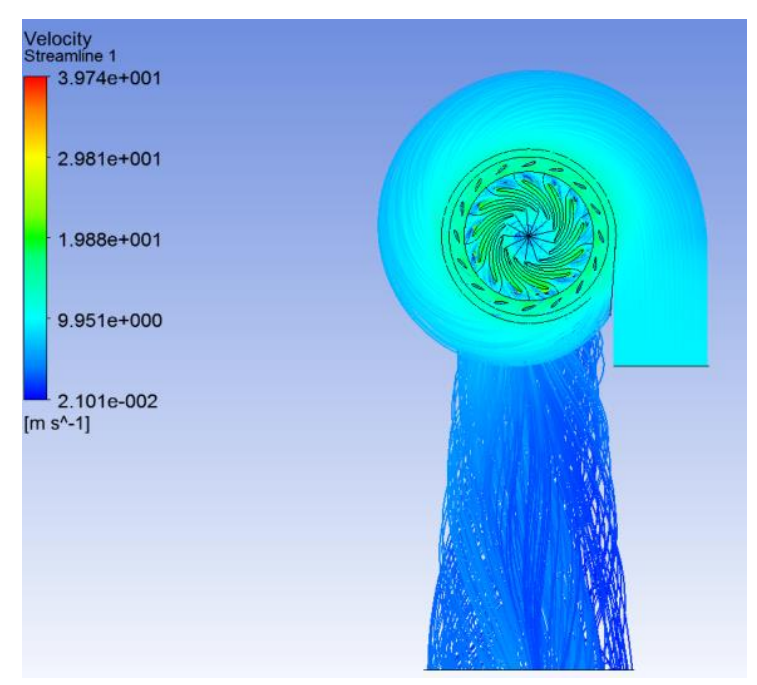

Şekil 21. Türbin Akış Hızı Dağılımı Önden Görünüm

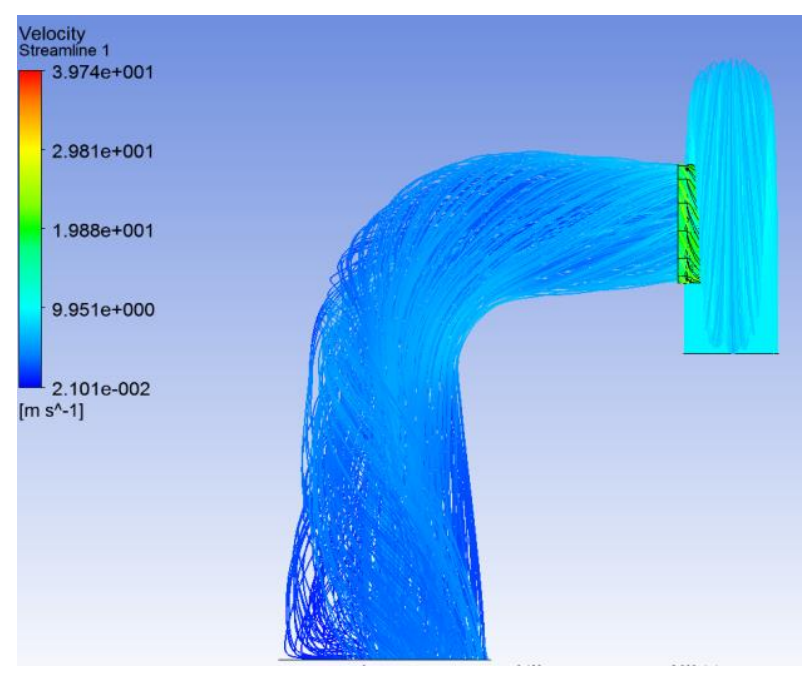

Şekil 22. Türbin Akış Hızı Dağılımı Soldan Görünüm 


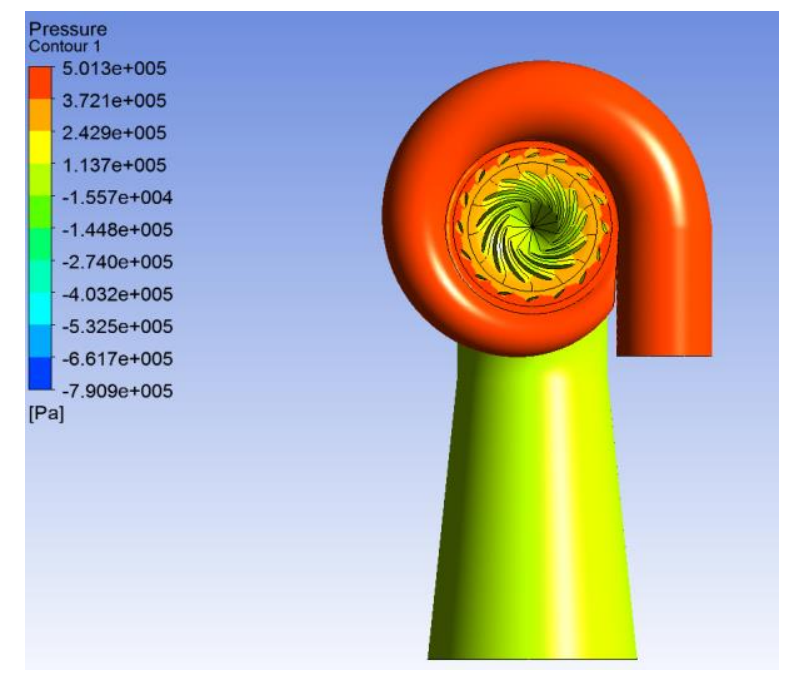

Şekil 23. Türbin Basınç Dağılımı Önden Görünüm

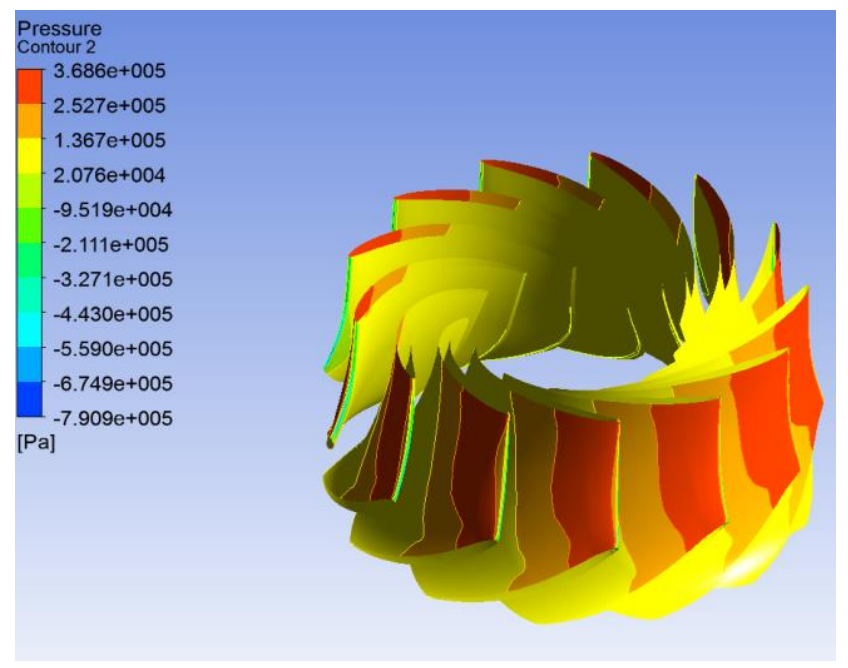

Şekil 24. Çark Kanatları Basınç Dağılımı

\section{Sonuç}

Bu çalışmada, Bovet yöntemine göre tasarlanan küçük ölçekli bir Francis türbinin HAD analizleri gerçekleştirilmiş ve verim değeri incelenmiştir. Bovet yöntemi çark tasarımı için deneysel bağıntıları kullanarak meridyenel düzlemde çark kanadı boyutlarını detaylı bir şekilde belirleyen bir yöntemdir. Bovet metodu ile kanat meridyenel profili elde edildikten sonra çark katı modeli oluşturulmuş ve çarkın verimliliğinin, basınç ve akış dağılımının, akış karakteristiklerinin hesaplanması için HAD analizleri gerçekleştirilmiştir.

Günümüzde, HAD analizleri yüksek verimli çark tasarımı için pratik bir yöntem olarak kullanılmaktadır. Türbin üreticileri HAD analizlerini, en güvenilir doğrulama yöntemi olan model türbin testleri ile doğrulamak zorundadırlar. Ancak, doğru metodolojiler ile oluşturulmuş olan güvenilir HAD analiz metotlarıda model türbin testleri gerçekleştirilmeden türbin üreticileri tarafindan kullanılmaktadır.

Çark için taahhüt edilen verim \%92'ydi, fakat HAD analizleri sonucunda çark için \%91,52 verim elde edilmiştir. Çark tasarımı gerçekleştirilirken kavitasyon oluşumu göz önünde bulundurulmalıdır. HAD sonuçlarına göre çark tasarımında yapılacak değişikliklerle kavitasyon bölgelerini gidermek mümkündür. Türbin için istenilen verim \%90'dı, fakat HAD analizleri sonucunda türbin bileşenlerindeki kayıplardan kaynaklı olarak \%88'lik verim değeri elde edilmiştir. Türbin HAD analizlerinde görüldüğü üzere çark üzerinde basıncın daha kademeli azalması için kanatlar üzerinde optimizasyon çalışması yapılması gerekmektedir. Emme borusundaki akışta oluşan bozulmaların düzeltilmesi gerekmektedir. Kavitasyon analizleri ile türbin üzerindeki oluşabilecek kavitasyon sorunlarının giderilmesi gerekmektedir. İlerleyen çalışmalarda tasarımdaki verim ile HAD analiz sonuçlarındaki verim arasındaki \%2'lik fark çark ve diğer türbin bileşenleri üzerinde yapılacak optimizasyon çalışmaları ve kavitasyon incelemeleri sonucu yapılacak iyileştirmeler ile giderilecektir. 


\section{Teşekkürler}

Bu çalışmaya yaptıkları katkılardan dolayı Arş. Gör. Eyup Koçak’a ve yüksek lisans öğrencisi olduğum Gazi Üniversitesi Fen Bilimleri Enstitüsü Makine Mühendisliği bölümüne teşekkürlerimi sunarım.

\section{Referanslar}

Ansys Inc. , (2013). CFX Solver Theory Guide. Release; 15: 79-90

Bovet T. , (1963). Francis Tipi Bir Reaksiyon Türbininde Çark Kanadının Çizimi, Lozan Üniversitesi

ESHA- European Small Hydropower Association, Guide on How to Develop a Small Hydropower Plant, (2004)

Ergin A. , (1972) Su Makinaları Ders Notları, İTÜ Makina Fakültesi

Haas R. , Hiebert M. , Hoatson E. , (2014). Francis Turbines, Fundamentals and Everything Else You Didn’t Know That You Wanted To Know, Colorado State University, CIVE 401

Huang J. , Swiderski J. , Ji J. , Tung T. , Riley M. , (2006). Francis Turbine Upgrade for the Lushui Generating Station by Using Computational Fluid Dynamics - A Case Study

Krivchenko G.I. , (1983). Hydraulic Machines: Turbines and Pumps

Laín S. , García M., Quintero B. , Orrego S. , (2010). CFD Numerical simulations of Francis turbines

Li J., WU Y., Liu S., Zhu Y, (2010). 3D Unsteady Turbulent Simulation of The Runaway Transient of The Francis Turbine Neopane P.H. , Dahlhaug G.O., Thapa B. , (2007). Alternative Design of a Francis Turbine for Sand Laden Water

Odesola I. F. , Oririabre J. I. , (2013). Development of a 5kW Francis Turbine Runner Using Computation Fluid Dynamics Ruprecht, Heitele, Helmrich, (2014). Numerical Simulation of a Complete Francis Turbine including unsteady rotor/stator interactions

Teran L.A. , Larrahondo F.J. , Rodriguez S.A. , (2016). Performance improvement of a 500-kW Francis türbine based on CFD

The USGS Water Science School - Hydroelectric power water use https://water.usgs.gov/edu/wuhy.html

Wang L. , (2012). The Optimal Design based on CFD Combined with CAD for Turbine Runner 